\title{
Operational reliability of low-voltage asynchronous motors at asymmetrical supply voltage
}

\author{
Victoria Romanova ${ }^{1 *}$, Sergey Khromov $^{1}$ \\ ${ }^{1}$ Trans-Baikal State University, Department of Electric Power Generation and Electrical Engineering, Russia, Chita, 30, Aleksandro- \\ Zavodskaya Str.
}

\begin{abstract}
Issues of operating modes of $4 \mathrm{~A}$ series asynchronous squirrel-cage motors and AI serried motors at asymmetrical supply voltage for different values of motor shaft load are considered on the basis of simulation using Matlab software package and Simulink package. In the simulation, currents in asynchronous motor phases were evaluated as a function of $\mathrm{K}_{2 \mathrm{U}}, \mathrm{K}_{\mathrm{Z}}$, and based on these results, permissible operation parameters were evaluated for induction motors. The results obtained are the basis for technical solutions aimed at improving operational reliability of asynchronous motors, they will allow taking into account permissible operating parameters of asynchronous motors not only in the design, but also in operation in power supply systems of various facilities.
\end{abstract}

\section{Introduction}

Reliability is the most important technical and economic indicator of asynchronous motors (AM) quality which defines ability to operate reliably with unchangeable technical characteristics during a given period of time under certain operating conditions $[1,2]$. However, in actual electric motor operation conditions, due to various factors, there is a significant deviation from normal operating modes. The vast majority of the reason for this is poor voltage quality in the networks, in particular, asymmetry of supply voltage. Supply voltage asymmetry has a negative impact on AM, reduces operational reliability and increases risk of motor failures. Thus, service life of asynchronous motors operating under full

\section{Materials and methods of the study}

The study of AM operating modes can be effective if computer simulation with virtual model implemented in a visual and effective simulation tool Simulink of interactive programming environment Matlab for $\mathrm{T}$ shaped induction motor equivalent circuit $[5,6]$ are used.

Simulation scheme for studying operation modes of asynchronous squirrel-cage motor, created by means of simulation in the Matlab/Simulink environment, is shown in (Fig.1). Using developed computer model, modes of squirrel-cage AM were studied taking into account the following:

- value of the motor shaft load varied from 0 to 120 $\%$ with $20 \%$ increments at different $\mathrm{K}_{2 \mathrm{U}}$ values, load is reduced by 2 times at a voltage asymmetry of $4 \%$. When the voltage is unbalanced by $5 \%$, available power of the motor is reduced by $5-10 \%[3,4]$.

In this paper, operation modes of $4 \mathrm{~A}$ series squirrelcage AM and AI series motors at asymmetrical supply voltage with different values of the motor shaft load were studied to identify AM operating modes.

Long-term trouble-free operation of AM is achieved as a result of implementation of measures aimed at maintaining technical and operational characteristics within the limits necessary for their trouble-free operation.

- value of reverse sequence voltage asymmetry coefficient was from 0 to $5 \%$ with $1 \%$ increments.

Study of series 4A and AI AM with a nominal motor speed $\mathrm{n}=1500 \mathrm{rpm}$, with a significant power spread from $5.5 \mathrm{~kW}$ to $200 \mathrm{~kW}$, was carried out. As an example, asynchronous squirrel-cage motors of $4 \mathrm{~A}$ series (4A132S4Y3 with $\mathrm{Pn}=7.5 \mathrm{~kW}$; 4A250S4Y3 with $\mathrm{Pn}=$ $75 \mathrm{~kW}$; 4A315M4Y3 with $\mathrm{Pn}=200 \mathrm{~kW}$ ) and of AI series (AIR132S4 with Pn $=7.5 \mathrm{~kW}$; AIR250S4 with Pn $=75 \mathrm{~kW}$; AIR355M6 with Pn $=200 \mathrm{~kW}$ ) were selected $[7,8]$.

\footnotetext{
* Corresponding author: romanova181@mail.ru
} 


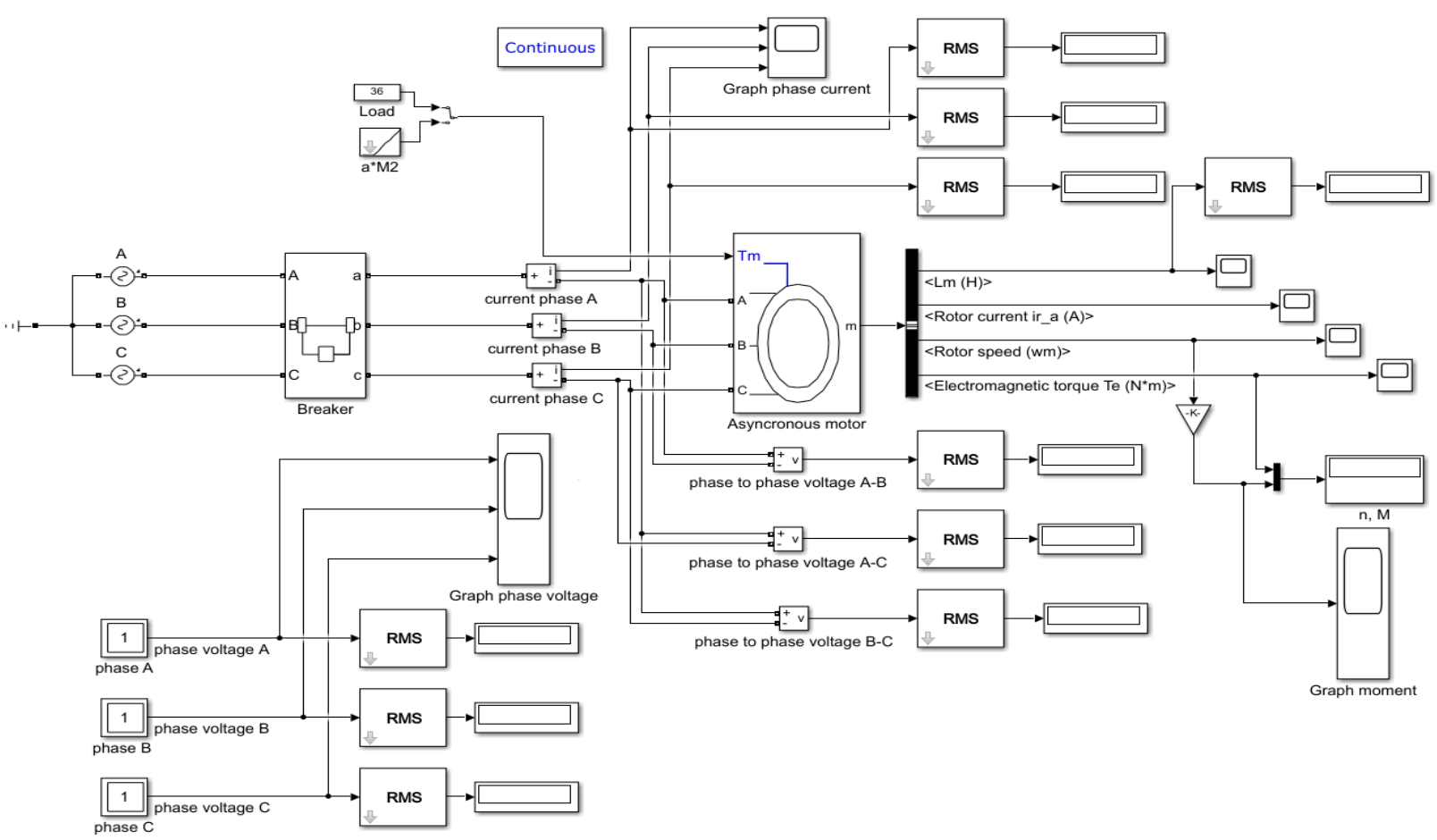

Fig.1. Simulation scheme implemented in Matlab/Simulink environment.

On the basis of the carried-out study, for each phase of the AM under consideration, dependences of currents versus $\mathrm{K}_{2 \mathrm{U}}$ were plotted for various values of motor shaft loads. Main types of current change in "A" phase for series 4A AM, AI with $\mathrm{Pn}=7.5 ; 75 ; 200 \mathrm{~kW}$, at different values of $\mathrm{K}_{2 \mathrm{U}}$ and different values of the motor shaft load are shown in (Fig.2-4). It should be noted that the control value of permissible overload current equal to 1.1 of the nominal current is taken into account when performing the studies $[9,10]$.

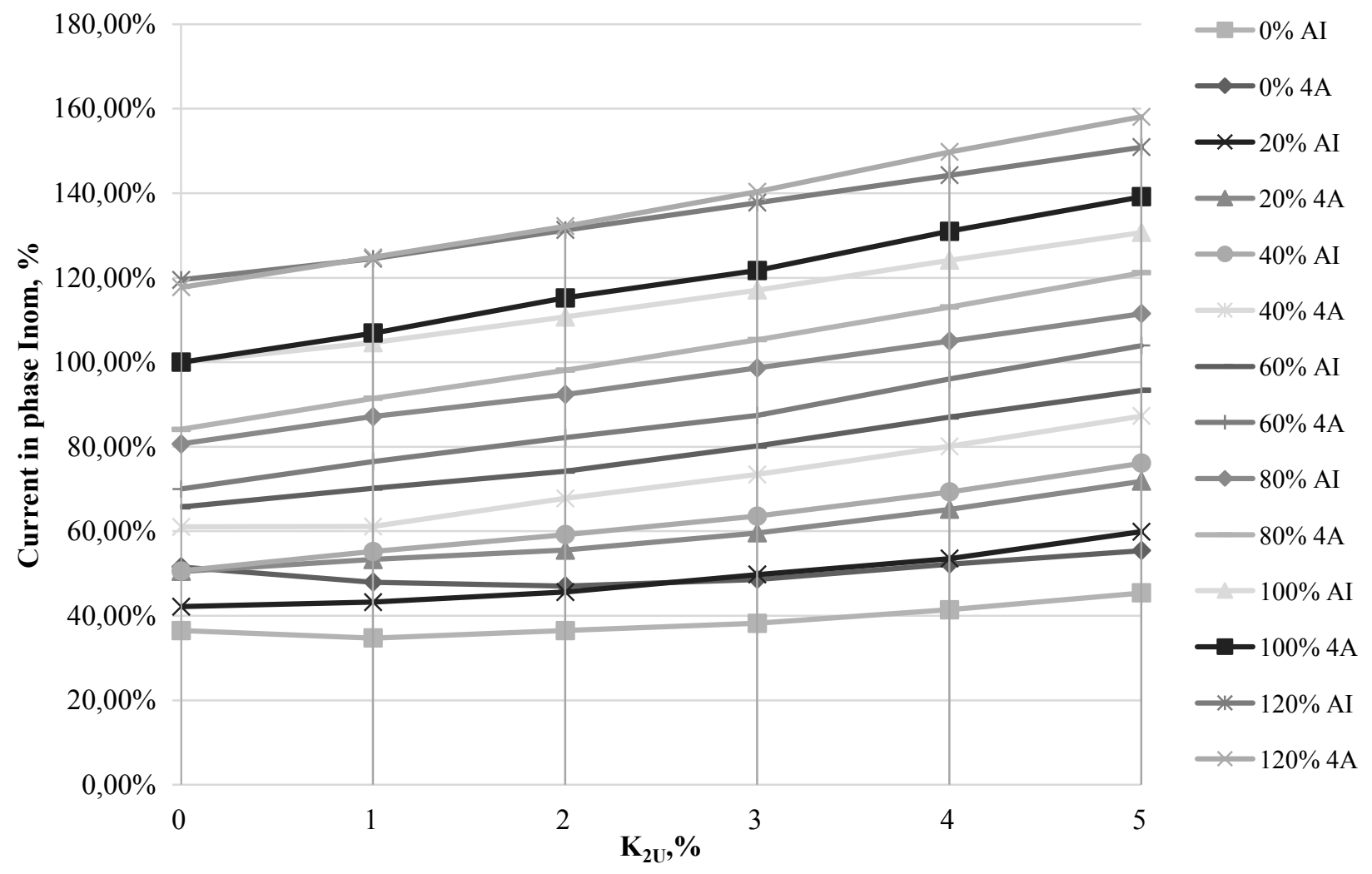

Fig.2. Curve of current in phase "A" AM series 4A, AI with $\mathrm{Pn}=7.5 \mathrm{~kW}$ from $\mathrm{K}_{2 \mathrm{U}}$ under different permanent load factors. 

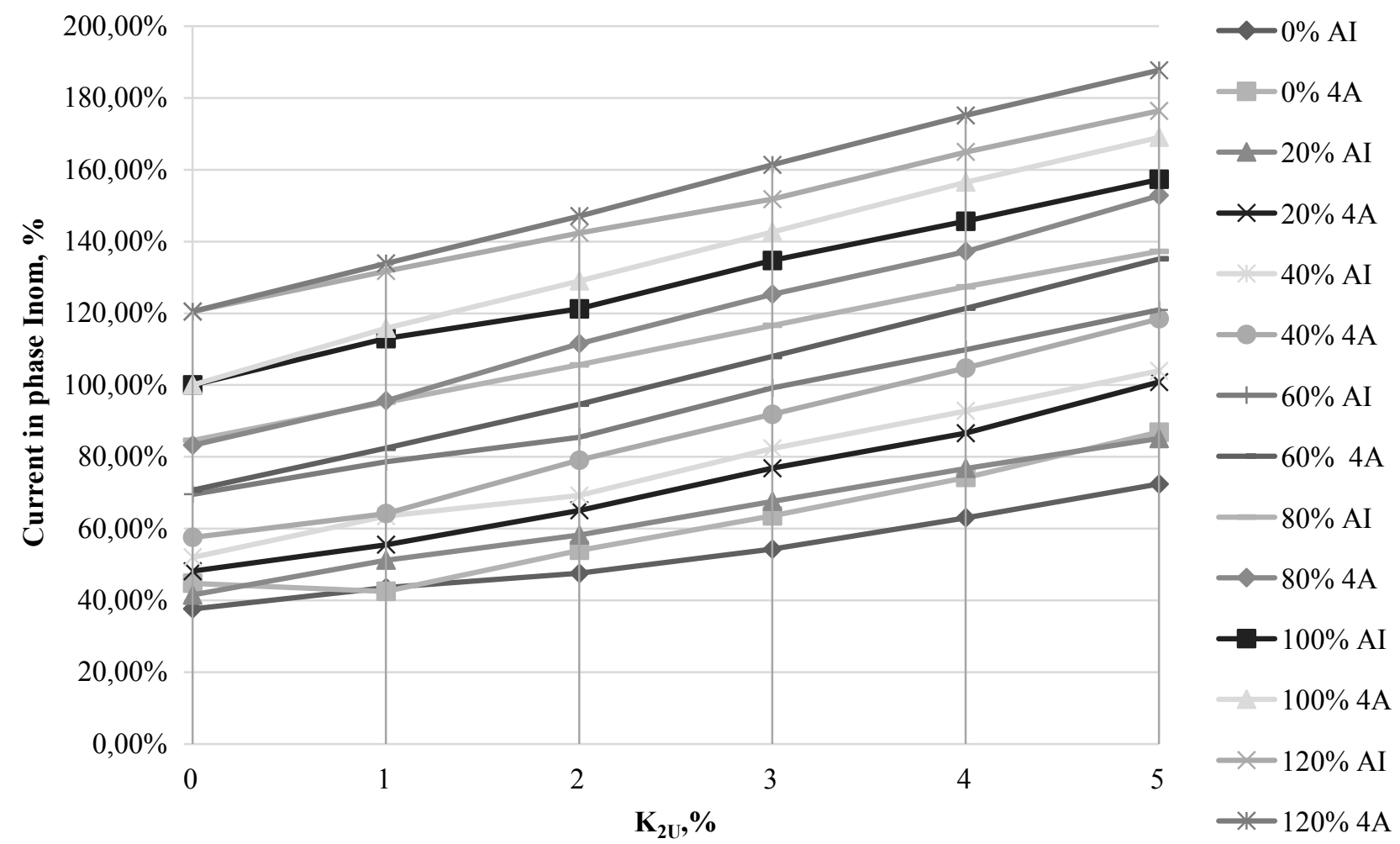

Fig.3. Curve of current in phase "A" AM series 4A, AI with $\mathrm{Pn}=75 \mathrm{~kW}$ from $\mathrm{K}_{2 \mathrm{U}}$ under different permanent load factors.
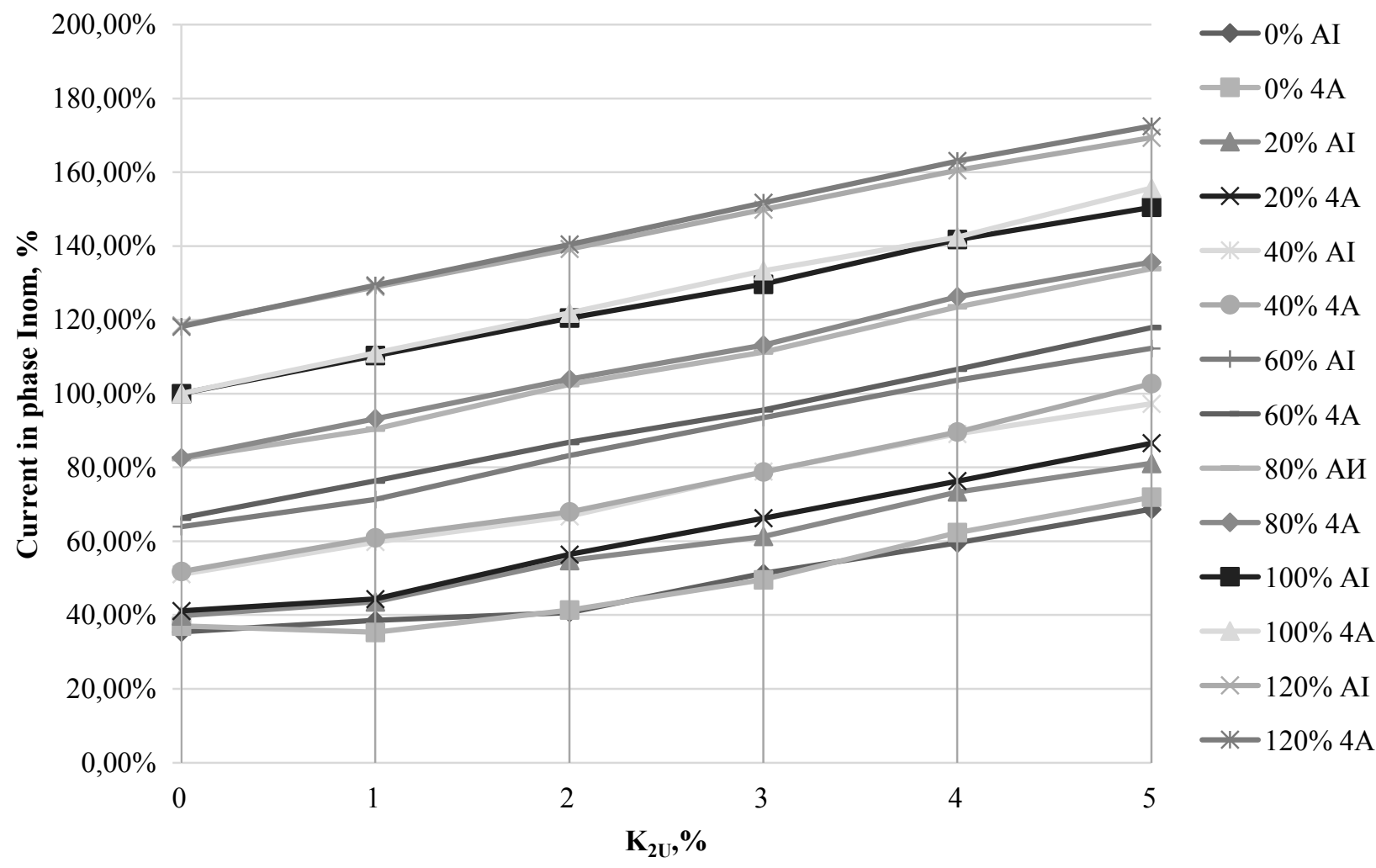

Fig.4. Curve of current in phase "A" AM series 4A, AI with $\mathrm{Pn}=200 \mathrm{~kW}$ from $\mathrm{K}_{2 \mathrm{U}}$ under different permanent load factors. 


\section{Results of the study and discussion}

On the basis of the results obtained in the course of computer simulation and using linear approximation of the data, analytical dependence of the AM current in the most loaded phase depending on the factors - reverse sequence voltage asymmetry coefficient $\left(\mathrm{K}_{2 \mathrm{U}}\right)$, load factor $(\mathrm{Kz})$, type of series and the electric motor power was derived.

The AM current dependence was defined by formula:

- for 4A series motor:

I $\%$ of I nom $=\left((-0.0002 \mathrm{P}+0.163) \mathrm{K}_{2 \mathrm{U}}+\right.$ $(0.8126 \mathrm{Kz}+0.081)) * 100, \%$
- for AI series motor:

I $\%$ of I nom $=\left((-0.0003 \mathrm{P}+0.1535) \mathrm{K}_{2 \mathrm{U}}+\right.$ $(0.8126 \mathrm{Kz}+0.081)) * 100, \%$

The conducted study allowed establishing the following regularities:

1) at supply voltage asymmetry, following indicators influence permissible AM parameters: power, load factor $(\mathrm{Kz})$ and coefficient of negative sequence voltage asymmetry $\left(\mathrm{K}_{2 \mathrm{U}}\right)$,

2) permissible AM operation parameters (at normal AM operation mode) are identified based on overload capacity.

Table 1. Permissible values of load factor AM series $4 \mathrm{~A}$, AI at different values $\mathrm{K}_{2 \mathrm{U}}$.

\begin{tabular}{|l|c|c|c|}
\hline \multirow{2}{*}{$\begin{array}{c}\text { Permissible Kz AM series 4A, AI } \\
\text { at different K2U }\end{array}$} & \multicolumn{3}{c|}{ Motor power capacity, $\mathbf{k W}$} \\
\cline { 2 - 3 } & $\mathbf{7 . 5}$ & $\mathbf{7 5}$ & $\mathbf{2 0 0}$ \\
\hline $\mathrm{Kz} 4 \mathrm{~A}$, of $\mathrm{K}_{2 \mathrm{U}}=0 \%$ & $110 \%$ & $110 \%$ & $110 \%$ \\
\hline $\mathrm{Kz} \mathrm{AI}$, of $\mathrm{K}_{2 \mathrm{U}}=0 \%$ & $110 \%$ & $110 \%$ & $110 \%$ \\
\hline $\mathrm{Kz} 4 \mathrm{~A}$, of $\mathrm{K}_{2 \mathrm{U}}=1 \%$ & $90 \%$ & $92 \%$ & $95 \%$ \\
\hline $\mathrm{Kz} \mathrm{AI}$ of $\mathrm{K}_{2 \mathrm{U}}=1 \%$ & $91 \%$ & $93 \%$ & $96 \%$ \\
\hline $\mathrm{Kz} 4 \mathrm{~A}$, of $\mathrm{K}_{2 \mathrm{U}}=2 \%$ & $70 \%$ & $74 \%$ & $80 \%$ \\
\hline $\mathrm{Kz} \mathrm{AI}$ of $\mathrm{K}_{2 \mathrm{U}}=2 \%$ & $73 \%$ & $76 \%$ & $82 \%$ \\
\hline $\mathrm{Kz} 4 \mathrm{~A}$, of $\mathrm{K}_{2 \mathrm{U}}=3 \%$ & $50 \%$ & $55 \%$ & $65 \%$ \\
\hline $\mathrm{Kz} \mathrm{AI}$, of $\mathrm{K}_{2 \mathrm{U}}=3 \%$ & $54 \%$ & $59 \%$ & $68 \%$ \\
\hline $\mathrm{Kz} 4 \mathrm{~A}$, of $\mathrm{K}_{2 \mathrm{U}}=4 \%$ & $31 \%$ & $37 \%$ & $49 \%$ \\
\hline $\mathrm{Kz} \mathrm{AI}$, of $\mathrm{K}_{2 \mathrm{U}}=4 \%$ & $35 \%$ & $42 \%$ & $54 \%$ \\
\hline $\mathrm{Kz} 4 \mathrm{~A}$, of $\mathrm{K}_{2 \mathrm{U}}=5 \%$ & $11 \%$ & $19 \%$ & $34 \%$ \\
\hline $\mathrm{Kz} \mathrm{AI}$, of $\mathrm{K}_{2 \mathrm{U}}=5 \%$ & $16 \%$ & $25 \%$ & $40 \%$ \\
\hline
\end{tabular}

3) the permissible value of $\mathrm{K}_{2 \mathrm{U}}$ is determined, when the engine is fully loaded

Table 2. Permissible values of coefficient asymmetry on the reverse sequence of AM series 4A, AI.

\begin{tabular}{|l|c|c|c|}
\hline \multirow{2}{*}{ Valid K2U AM series 4A, AI } & \multicolumn{3}{|c|}{ Motor power capacity, $\mathbf{k W}$} \\
\cline { 2 - 4 } & $\mathbf{7 . 5}$ & $\mathbf{7 5}$ & $\mathbf{2 0 0}$ \\
\hline $\mathrm{K}_{2 \mathrm{U}} 4 \mathrm{~A}$ & 1.28 & 1.39 & 1.68 \\
\hline $\mathrm{K}_{2 \mathrm{U}} \mathrm{AI}$ & 1.36 & 1.58 & 2.21 \\
\hline
\end{tabular}

Thus, permissible values of $\mathrm{K}_{2 \mathrm{U}}$ are different not only for different AM series, but they also vary within the motor series, and they directly dependent on the motor power.

In accordance with standards GOST 32144-2013, permissible AM operating parameters are:

a) at $\mathrm{K}_{2 \mathrm{U}}$ from $0 \%$ to $2 \%$, range of normal operating modes of $4 \mathrm{~A}$ series $\mathrm{AM}$ is $\mathrm{Kz}$ from $0 \%$ to $70 \%$, range of normal operating modes of $\mathrm{AI}$ series $\mathrm{AM}$ is $\mathrm{Kz}$ from $0 \%$ to $80 \%$,

b) at $\mathrm{K}_{2 \mathrm{U}}$ from $2 \%$ to $4 \%$, range of normal operating modes of $4 \mathrm{~A}$ series $\mathrm{AM}$ is $\mathrm{Kz}$ from $0 \%$ to $31 \%$, the range of normal operating modes of $\mathrm{AI}$ series $\mathrm{AM}$ is $\mathrm{Kz}$ from $0 \%$ to $35 \%$.

In the case of long-term operation, normal AM operation at $\mathrm{K}_{2 \mathrm{U}}=2 \%$ is possible with reduced load:

- for $4 \mathrm{~A}$ series motor with $\mathrm{Pn}=7.5 \mathrm{~kW}$ - to $70 \%$, for AI series motor with $\mathrm{Pn}=7.5 \mathrm{~kW}$ - to $73 \%$,

- for $4 \mathrm{~A}$ series motor with $\mathrm{Pn}=75 \mathrm{~kW}$ - to $74 \%$, for AI series motor with $\mathrm{Pn}=75 \mathrm{~kW}-$ to $77 \%$,

- for $4 \mathrm{~A}$ series motor with $\mathrm{Pn}=200 \mathrm{~kW}$ - to $80 \%$, for AI series motor with $\mathrm{Pn}=200 \mathrm{~kW}$ - to $82 \%$.
4) permissible $K_{2 U}$ range (in the case of $A M$ normal operation) at full load of the motor is defined as follows:

- for 4A series motor with $\mathrm{Pn}=7.5 \mathrm{~kW}$ - allowable $\mathrm{K}_{2 \mathrm{U}}$ range is from 0 to $1.28 \%$, for AI series motor with $\mathrm{Pn}=7.5 \mathrm{~kW}$ - allowable $\mathrm{K}_{2 \mathrm{U}}$ range is from 0 to $1.36 \%$,

- for $4 \mathrm{~A}$ series motor with $\mathrm{Pn}=75 \mathrm{~kW}$ - allowable $\mathrm{K}_{2 \mathrm{U}}$ range is from 0 to $1.39 \%$, for AI series motor with $\mathrm{Pn}=75 \mathrm{\kappa BT}-$ allowable $\mathrm{K}_{2 \mathrm{U}}$ range is from 0 to $1.58 \%$,

- for 4A series motor with $\mathrm{Pn}=200 \mathrm{~kW}$ - allowable $\mathrm{K}_{2 \mathrm{U}}$ range is from 0 to $1.68 \%$, for AI series motor with $\mathrm{Pn}=200 \mathrm{~kW}$ - allowable $\mathrm{K}_{2 \mathrm{U}}$ range is from 0 to $2.21 \%$.

As a result of the study on influence of main factors on AM operation mode, it should be noted:

1) regulation of $\mathrm{K}_{2 \mathrm{U}}$ should be performed based on the permissible operating modes of motors and their commercially available models. It was found that, at long-term or repetitive voltage asymmetry, technical balancing means with output asymmetry of not more than $1.3 \%$ should be provided for AM power supply sources even if $\mathrm{K}_{2 \mathrm{U}}$ value complies with requirements of GOST 32144 - 2013 [11],

2) necessity of optimal solution to change AM load or application of input technical balancing means in 
power supply system is defined primarily by following factors: technical and economic analysis of the solution feasibility; nature of asymmetry in the network; features of the production process in the enterprise. Based on the obtained data on permissible $\mathrm{Kz}$ value, technical balancing means should be applied for $\mathrm{AM}$ when $\mathrm{K}_{2 \mathrm{U}}=$ $1.3 \%$ is reached; if $\mathrm{K}_{2 \mathrm{U}}$ exceeds this value, it is necessary to reduce the AM load. So, for example for 4A series $\mathrm{AM}$ with $\mathrm{Pn}=7.5 \mathrm{~kW}$ at $\mathrm{K}_{2 \mathrm{U}}=3 \%$, it is necessary to reduce the load by $50 \%$; for $4 \mathrm{~A}$ series $\mathrm{AM}$ with $\mathrm{Pn}=200$ $\mathrm{kW}$ at $\mathrm{K}_{2 \mathrm{U}}=3 \%$ - by $35 \%$. When the motor load is reduced, range of normal operating mode is doubled. If the technological process of the enterprise and drive mechanisms connected to the AM care able reduce the load, this method can be more cost-effective in the short production term than installation of technical balancing means or purchasing of more powerful AM,

3 ) in the AM operating conditions, when power supply network containing electric motor equipment is designing, it is necessary to take into account influence of permissible $\mathrm{K}_{2 \mathrm{U}}, \mathrm{Kz}$ values. This will increase reliability and efficiency of asynchronous motors and power supply systems in general.

\section{Conclusion}

By means of computer simulation experiments, using Matlab software package and Simulink package, permissible operating parameters of asynchronous motors were defined. Quantitative evaluation of main factors influencing AM operation mode is shown with examples. This study results can be used to solve problems of power quality management optimization at enterprises.

The work was executed within the framework of FSBEI HPE Trans-Baikal State University Council for Research and Innovative Activities Scientific Grant No. 276-GR of $01 / 02 / 2019$ implementation.

\section{References}

1. N. Kuznetsov, Reliability of electric machines. M.: Publishing house MEI, 432 (2006).

2. N. Ermolin, I. Zherikhin, Reliability of electric machines. - L.: Energy, 248 (1976).

3. I. Zhezhelenko, Yu. Sayenko, A. Gorpinich, I. Shvetsova, Priazovsk National Technical University Reporter: Collection of scientific articles / PNTU. - Mariupol Issue 15, P.2., 25 - 29 (2005).

4. M. Sorkind, Electric Engineering News. Information and Reference Publishing House No. 2 (32), (2005).

5. S. German-Galkin, G. Kardonov, Electrical machines: Laboratory works with PC. - SBR: Korona-print, 256 (2003).

6. I. Chernykh, Simulation of electrical devices using MATLAB, SimPowerSystems and Simulink. SBR: Piter M.: DMK Press, 288 (2008).

7. http:// principact.ru/content/view/166/72/

8. http://www.elektrikii.ru/publ/6-1-0-55

9. www.bmrzzakharov.narod.ru/raschet/overload.html

10. V. Kogorodsky, S. Kuzhekov, L. Paperno, Relay protection of motors with voltage above $1 \mathrm{kV}$. M.: Energoatomizdat, 248 (1987).

11. GOST 32144 - 2013. Electrical power. Electromagnetic compatibility of technical equipment. Electrical power quality standards in the general-purpose power supply systems. - M.: Standartinform, 19 (2014). 